Aims A survey assessing patient understanding of, and views on, confidentiality and data sharing in sexual health.

Methods Data were collected using a questionnaire distributed to 203 consecutive patients seen in our busy inner-city sexual health clinic and analysed using Microsoft Excel 2007.

Results The 90 respondents demonstrated a good understanding of the definition of confidentiality ( $92 \%)$. Of the 54 respondents that were happy for information to be shared, $9 \%$ preferred this to be in paper format, $37 \%$ electronic, $54 \%$ were happy with both. $30 \%$ would be happy with medical record sharing between sexual health clinics, and $58 \%$ of these would prefer this information to be shared locally rather than nationwide. $50 \%$ agreed with the use of a shared database between our Trust's sexual health centres.

Conclusion Patients understand the concept of confidentiality. Pertinent to the increasing use of electronic patient records, patients prefer the transfer of information to be in an electronic format. Opinions vary on data sharing practices, and at present, half of patients agree with the prospect of a shared database.

\section{P105 THE INTERNET AS A SOURCE OF SEXUAL HEALTH INFORMATION; WHAT DO SERVICE USERS WANT?}

doi:10.1136/sextrans-2012-050601c.105

F Eddy, ${ }^{*}$ M Brady. King's College London

Background Access to information is a key challenge in sexual health, with poor knowledge associated with poor outcomes. Internet interventions have been shown to improve sexual health knowledge, highlighting the potential of the web as a source of information.

Aims To assess sexual health service users' use of the Internet to obtain sexual health information, and to use the data to inform the design of a local sexual health website.

Methods 243 participants were recruited from a busy walk-in sexual health clinic in July and September 2011. A structured questionnaire assessed their use and rating of the Internet for various aspects of sexual health information (STIs, contraception, clinic information, homosexuality, virginity and body worries) and gauged opinion on the content of a local sexual health website.

Results $62 \%$ of participants were female. $44 \%$ identified as black African, black Caribbean or black British and $42 \%$ were white. $44 \%$ were aged under $25.67 \%$ of respondents use the internet for sexual health information. It was the most popular resource for information on STIs, clinic information and homosexuality (compared to doctor/nurse, friends, family, school, TV and magazines). The next most popular choices were doctor/nurse and friends. $67 \%$ stated they would use a local sexual health website with STIs, clinic information and contraception being the topics they would most like information on. "Detailed" and "Basic" information were highlighted as important aspects of website content. Only 19\% selected "original design" as being important.

Conclusions The internet is a popular source for sexual health information. For STIs it was selected over doctors/nurses indicating the need for good online information. Both basic and detailed information were requested highlighting the importance of a range of educational resources. Originality was not as important as having a site they could trust. These findings will inform the development and content of a local website.

\section{P106 \\ POST (ZIP) CODE POWER: A NEW WEB/SMS TOOL TO MARKET PROVIDERS AND SIGN POST CLIENTS}

doi:10.1136/sextrans-2012-050601c.106

A Menon-Johansson. ${ }^{*}$ Guy's \& St Thomas' NHS Foundation Trust, London, UK

Introduction Helping clients to find the right service in the right place at the right time is important for individual and public health. Many websites try to address this; however, providers lack control of their web profile and the accuracy of sign posting varies. A free confidential web/SMS service (http://www.sxt.org.uk) was therefore developed to support both providers and clients. All texts are charged at the standard SMS rate. Data collected were then evaluated for service utility, ability to provide gap analysis, met and unmet need and the capture of client feedback.

Methods Web site traffic was analysed by Google analytics whilst SMS usage, provider sign up, met and unmet need and gap analyses were made possible from data downloads. Marketing was initiated by business card adverts to South London colleges and MSM venues as well by Google Ads to London users.

Results There are currently 23 providers of sexual and reproductive health in SXT across 10 London boroughs. These providers include hospital and community sexual health clinics, primary care physicians and pharmacies. In addition, out of hours post-exposure prophylaxis providers and the three sexual assault referral centres have been included in SXT. All early adopters were able to edit their profile and add services within 20 min. Over 3 months, 701 unique visitors viewed the website with a bounce rate of $41 \%$. Gap analyses of key services have been produced to inform service development in the London boroughs of Lambeth and Southwark. The SMS service had 74 users and the met need was 32\%. Only 31 (0.04\%) of all web and SMS users opted-in to provide qualitative feedback.

Conclusion A scaleable web/SMS tool has been developed to match provider services with client needs that both supports local marketing initiatives and captures client feedback. Additional provider, client and commissioner feedback is required to optimise SXT.

\section{P107 CYBERSPACE AND SEXUAL HEALTH: AN OBJECTIVE REVIEW OF WEBSITE QUALITY AND NAVIGABILITY}

doi:10.1136/sextrans-2012-050601c.107

J Sutherby, ${ }^{*}$ A S Menon-Johansson. Department of Sexual Health, Guy's \& St Thomas NHS Foundation Trust, London, UK

Background Sexual health providers/organisations are increasingly using the web as a powerful tool to market their services and educate people.

Objective This study explored the quality of sexual health websites in the UK in order to help facilitate learning and development.

Methods 7 websites were selected to represent a range of providers (eg, NHS vs charitable organisations) and target audience (youth vs adult). The following areas were rigorously analysed: (1) Common content (2) Clarity (quality of flow/ease of navigation) (3) Innovative features and (4) Number of clicks to important information (see abstract 107 table 1).

Results Common content covered by the websites were Clinic Information, Contraception, Pregnancy, STIs, HIV, Sex/

Abstract P107 Table 1 Number of clicks required to reach information according to website

\begin{tabular}{|c|c|c|c|c|c|c|c|}
\hline Number of clicks to ... & Cambridge & Kingston & SWISH & Brook & Birmingham & THT & NHS choice \\
\hline Emergency Contraception & 1 & 1 & 2 & 1 & 2 & 3 & 2 \\
\hline Post Exposure Prophylaxis & 1 & 1 & 2 & Cannot find & Cannot find & 3 & Hard to find \\
\hline STI test 'specifically' for Gay men & Cannot find & 2 & 2 & Cannot find & Cannot find & 2 & No search function \\
\hline Number of Innovative features & 3 & $>5$ & $>5$ & $>10$ & $>10$ & $>10$ & 1 \\
\hline
\end{tabular}

